SÁVIO, Marco Antônio Cornacioni. As guerras de Minerva: a Revista Politénica e a construção de uma ideia de ciência em São Paulo, 1904-1917. História, Ciências, Saúde - Manguinhos, Rio de Janeiro, v.20, supl., nov. 2013. p.1315-1332.

\title{
As guerras de Minerva: a Revista Politécnica e a construção de uma ideia de ciência em São Paulo, 1904-1917
}

War of Words: Revista Politécnica and the construction of an idea of science in São Paulo, 1904-1917

\footnotetext{
Marco Antônio Cornacioni Sávio

Professor da Faculdade de Ciências Integradas do Pontal/ Universidade Federal de Uberlândia e do Programa de Pós-graduação em Ciências Humanas e Sociais/Universidade Federal do ABC. Rua Eduardo Márquez, 931/501

38400-448 - Uberlândia - MG - Brasil

marco.savio@hotmail.com
}

Recebido para publicação em março de 2011.

Aprovado para publicação em abril de 2012.

\section{Resumo}

O artigo discute o papel da Revista Politécnica na criação de uma ideia de ciência em São Paulo, durante a Primeira República. Instituição marcada pela controvérsia ao longo de seus primeiros anos, a Escola Politécnica de São Paulo teve na revista publicada por seus estudantes órgão de defesa e difusor de uma ideia de ciência para as elites paulistas do período. Esse meio de difusão, além de garantir local de destaque para a instituição no estado, possibilitou sua consolidação como centro científico nacional em oposição, por exemplo, à principal instituição concorrente, a Escola Politécnica do Rio de Janeiro.

Palavras-chave: ciência; divulgação científica; política; instituições; Brasil.

\section{Abstract}

This article discusses the role of the journal, Revista Politécnica in the creation of an idea of science in São Paulo during the first republican period in Brazil. Published by the students of the Escola Politécnica de São Paulo (São Paulo Polytechnic), which went through upheavals in its formative years, the periodical became a vehicle for the promotion and communication of an idea of science amongst the São Paulo elites at the time. It not only assured the institution a prominent position in the state, but also helped its consolidation as a national center of science, as opposed, for instance, to its main competitor, the Escola Politécnica do Rio de Janeiro (Rio de Janeiro Polytechnic).

Keywords: science; science communication; politics; institutions; Brazil. 
$\mathrm{A}^{\mathrm{s}}$ Escola Politécnica ocupa hoje papel de destaque no cenário da produção científica e tecnológica nacional. A historiografia a seu respeito, em boa parte graças a sua condição entre as instituições científicas brasileiras, está calcada num conjunto de grandes feitos que alguns pesquisadores da história da ciência recorrentemente trazem à tona (Motoyama, Nagamini, 2004). Se, no entanto, observarmos mais atentamente a história daquela instituição, veremos que ela não foi sempre unanimidade nem representava os grandes anseios de modernização das elites na época de sua fundação.

O objetivo deste artigo é analisar as contradições dos discursos que envolvem a Escola Politécnica de São Paulo, além de destacar algumas vozes discordantes acerca do projeto representado pela instituição paulista, também procurando demonstrar as estratégias usadas para a criação de uma ideia de ciência entre as elites paulistas no início do século passado. Para tanto, analisa-se o principal órgão de divulgação científica da escola, a Revista Politécnica, fundada em 1904 pelos alunos da instituição, com o principal intuito de difundir para toda a sociedade paulista os trabalhos realizados nas dependências do suntuoso prédio do antigo solar do marquês de Três Rios. O período analisado vai da data da fundação da Revista, em 1904, até a morte do primeiro diretor da instituição, e um dos mais famosos nomes da história da Escola Politécnica, Antônio Francisco de Paula Souza, em 1917.

Em uma perspectiva histórica, a Escola Politécnica surgiu em período de grande florescimento do interesse acerca do estudo das engenharias no Brasil. Inaugurada em 1894, surge em momento no qual outras escolas do gênero são fundadas país afora. Diferentemente das duas mais antigas instituições técnicas do Brasil, a Real Academia Militar, no Rio de Janeiro, de 1810, e a Escola de Minas de Ouro Preto, de 1876, a escola paulista nasce em ambiente federativo, respondendo a interesses regionais e não a projeto de caráter nacional, no sentido hoje dado ao termo. $\mathrm{O}$ aparecimento dessas instituições atendia às necessidades geradas pelo processo de modernização da infraestrutura no Brasil, como a criação de portos, ferrovias, melhorias nos serviços nas grandes cidades do país, como São Paulo e Rio de Janeiro, demandando a formação de um corpo de engenheiros para abastecer um mercado de trabalho que se ampliava a cada dia (Nagamini, 2004, p.196-197).

Nesse sentido, o surgimento dessas instituições fazia parte de um esforço para o desenvolvimento do ensino técnico-científico. Fortemente influenciados pelo positivismo, os responsáveis pela difusão do ensino superior no Brasil ansiavam pela disseminação de escolas de ensino técnico superior, vinculando a expansão do pensamento científico às ideias de modernidade e progresso. No entanto, os modelos que deviam ser seguidos por essas escolas eram razão de acirrada discussão entre grupos da intelectualidade (Schwartzman, 2001, cap.4). Certamente, o modelo mais atraente era aquele representado pelos institutos, que possuíam forte influência da cultura científico-acadêmica francesa e que tinham entre os intelectuais e cientistas ligados ao positivismo seus mais arraigados defensores.

Outro modelo era o das escolas politécnicas, que, oposto ao dos institutos, procurava aliar o ensino de diversas modalidades de engenharias com sua aplicação prática. Essas diferenças não constituíam meros aspectos de política educacional, tratando-se antes de questões de cunho político e ideológico. Os positivistas tinham fortes argumentos e grande influência na política nacional do período, e defendiam que o ensino superior deveria ser deixado nas mãos da iniciativa privada, cabendo ao Estado cuidar apenas do ensino básico. De outro lado 
estavam aqueles que apostavam num modelo de escola como as politécnicas, ligadas em boa parte a grupos liberais e defensores do ensino superior como prioridade do Estado.

A instituição paulista foi fundada a partir do projeto de lei n.9, de 1892, do então deputado estadual Antônio Francisco de Paula Souza, que propunha a criação de uma escola nos moldes do Instituto Politécnico de Zurique, em que Paula Souza aprendeu a profissão de engenheiro, aliando o ensino teórico à aplicação prática "nas artes e na indústria" (Nagamini, 2004, p.199). Essa ideia, no entanto, concorria com outros projetos e recursos para a fundação de escolas superiores no estado, entre os quais estavam os de criação de uma escola de farmácia, uma de engenharia e uma agrícola, todas contando com a simpatia dos membros da Assembleia Estadual Paulista.

Além de disputas internas no seio do Partido Republicano Paulista, o PRP, outras figuras ilustres no cenário científico nacional logo se colocaram contrárias ao projeto da Escola Politécnica, sendo a mais ilustre delas o engenheiro Euclides da Cunha. Em dois artigos publicados no principal jornal de São Paulo na época, O Estado de São Paulo, Euclides da Cunha ataca duramente a proposta de Paula Souza. Entre seus argumentos estavam a contrariedade ao ensino superior financiado pelo Estado e o descontentamento com o projeto de um curso em que a prática antecedia o aprendizado teórico (Vargas, 1994a, p.16-17). Essa crítica não era voz solitária no estado nem no restante da federação, principalmente na capital da República. Fato é que havia uma disputa dentro do PRP acerca de qual projeto de ensino superior deveria ser seguido.

Na verdade, o único ponto de contato entre esses grupos consistia no discurso em prol do desenvolvimento científico e da necessidade de modernização do país. Os caminhos propostos para isso eram, no entanto, bastante diversos, incluindo-se o modelo de ensino científico e até o próprio sentido da palavra ciência. Essa situação tornava necessária para os defensores do modelo da Escola Politécnica não apenas angariar votos, mas também conquistar opiniões favoráveis à instituição. Para isso, os fundadores da escola aliaram o discurso normalmente relacionado às engenharias ao da 'praticidade' e do 'progresso'. Esse discurso transformaria a Escola Politécnica em aliada do progresso material paulista e difusora dos valores propagados pela autoimagem dos paulistas como os 'yankees da América do Sul'. Após alguns embates na Câmara dos Deputados, finalmente a fundação da Escola Politécnica foi aprovada através da lei 191, de 1893, tendo a aula inaugural da instituição ocorrido no início do ano seguinte.

A administração da escola ficou a cargo de seu idealizador, Paula Souza, que esteve à frente da instituição até sua morte, em 1917. A organização da primeira estrutura curricular coube a Sales de Oliveira, Theodoro Sampaio e Coronel Jardim, tendo como base o disposto na lei 191. O primeiro regulamento criou uma instituição cuja base curricular não contemplava a exigência obrigatória de frequência, permitia a existência de alunos ouvintes e se utilizava de alguns subterfúgios para atrair interessados em seguir longa e difícil grade curricular, entre eles, o prêmio, concedido ao melhor aluno, de uma viagem ao exterior, financiada pelo tesouro do Estado (Nadai, 1987, p.59-60). Essa iniciativa só acentuou as críticas ao dispendioso projeto da escola. A falta de uma cadeira de química e a obrigatoriedade do curso de latim eram exemplos das principais críticas àquilo que os deputados paulistas chamavam de excentricidades numa escola superior de engenharias. 
Em decorrência, criou-se um segundo regulamento, no mesmo ano, com o único intuito de responder às críticas recebidas por parte dos membros do Legislativo. Esse novo regulamento determinou um curso de formação básica para os alunos, já que grande parte deles chegava despreparada para enfrentar as disciplinas da área de exatas, e uma série de etapas para que o interessado obtivesse o diploma de engenheiro politécnico. Para evitar o desinteresse dos alunos em seguir um curso longo, criou-se uma série de títulos que serviriam de premiação àqueles alunos que cursassem as várias etapas da grade curricular fundamental. Os que terminassem o curso preliminar (equivalente ao primeiro ano) receberiam o título de contador; os que concluíssem o curso geral (equivalente ao segundo ano) receberiam o título de agrimensor; e aqueles que completassem o curso fundamental (equivalente ao terceiro ano) receberiam o título de engenheiro geógrafo (Nadai, 1987, p.61-62). Os dois anos seguintes eram reservados à especialização nas diversas cadeiras de engenharia.

Dessa forma, os diretores da Politécnica procuravam responder a seus acusadores e criar um ambiente em que os estudos científicos pudessem desenvolver-se de forma concreta. O desafio, portanto, era o de criar uma instituição que fosse amplamente aceita pela sociedade e pelas outras instituições e que conquistasse um espaço político dentro do estado. A conquista desse espaço é fundamental para qualquer instituição de ciência, já que seu discurso só se torna efetivo se aceito pela comunidade científica como um todo, e, para tanto, era necessário não apenas produzir ciência, mas também explicar às pessoas o que isso significava (Barnes, Bloor, Henry, 1996, p.140-168; Bloor, 1978, p.247-248) e como era possível para a Politécnica produzir conhecimento científico aliado aos interesses políticos das elites de São Paulo.

A tarefa de divulgação do trabalho científico desenvolvido pela instituição teve como um de seus principais executores o Grêmio Politécnico, estabelecido pelos alunos da instituição, que a desempenhava por meio da Revista Politécnica, editada nas gráficas da Tipografia do Estado. Coube ao periódico importante papel na divulgação de uma ideia de ciência e na construção de fronteiras que garantiriam a credibilidade da instituição. Além disso, suas páginas abrigariam importantes discussões acerca das questões técnicas que envolviam aspectos centrais da administração pública na cidade de São Paulo.

\section{A Revista Politécnica e o papel da divulgação científica}

A Revista Politécnica transformou-se, ao longo dos anos, em uma das principais revistas científicas brasileiras. De órgão do Grêmio Politécnico, fundado pelos alunos da escola, transformou-se em veículo de divulgação do trabalho de professores da instituição. Em seus primeiros 14 anos, os artigos publicados baseavam-se em grande parte em anotações de aulas. Pesquisas inéditas, propriamente, eram algo raro a figurar entre os assuntos nos primeiros anos da Revista. ${ }^{1}$ A ausência de textos inéditos, no entanto, era compensada pelo trabalho de divulgação de uma ideia de ciência, incluindo tanto o modo de produção dessa ciência como seu entendimento pelos alunos do Grêmio Politécnico.

A Revista foi fundada por Hipólito Gustavo Pujol Jr., que se tornaria professor na instituição, Paulo de Vargas Cavalheiro e Francisco Osório Mascarenhas, entre outros, e, em seu número inaugural, apresenta sua carta de intenções ao se declarar uma publicação 
de estudo, modesta e simples, ela não tem diante de si outra derrota senão a que conduz à elevação moral e intelectual daqueles que em torno dela se juntarem. ... Órgão do Grêmio Politécnico, ela defenderá sempre, e com energia, o seu interesse, que é o de todos nós, como o da classe a que todos nos destinamos. ... Aberta à colaboração de quantos, entre nós, labutam pelo saber como pelo ensino, ela refletirá a perfeita solidariedade que nos une no estudo e nos confunde no mesmo e sagrado empenho de aprender (Albuquerque, nov. 1904, p.4).

De fato, atribuía-se o papel de defender os interesses de uma classe que precisava afirmarse em meio a uma sociedade que não valorizava nem compreendia aquela forma de saber. Talvez por isso a Revista Politécnica, em seus primeiros anos, se tenha transformado em veículo para os mais diversos assuntos. Nela não havia seções fixas, com exceção da seção de notas, presente no final de cada número, tratando de fatos da vida acadêmica da instituição e de eventos diversos no Brasil e no exterior. Tirando algumas edições comemorativas, as edições eram compostas por artigos tratando de assuntos diversos, notas de aula, anotações de conferências e exercícios sobre tópicos mais complexos. Em meio aos assuntos próprios do discurso dos politécnicos, como álgebra, concreto, eletricidade e mecânica, por exemplo, pincelavam-se artigos sobre exposições de arte, literatura, biografias diversas e até didática.

Essas escolhas editoriais refletem não apenas o clima intelectual dos primeiros anos do século XX, mas também as tensões e disputas que envolviam o papel da Escola Politécnica na estrutura educacional do estado de São Paulo. Disputas, aliás, ligadas também ao próprio modelo de educação que o governo estadual construía então. Como reflexo disso, a Revista Politécnica adotava estratégia discursiva que tinha por objetivo difundir uma ideia de ciência que, de um lado a legitimasse e, de outro, criasse para a instituição um papel que fosse aceitável no discurso de progresso marcado por uma difusa ideia de empreendedorismo e conhecimento prático, ou seja, de uso imediato, respondendo às expectativas e aos problemas que afligiam a sociedade.

Tradicionalmente a divulgação científica tem importante papel naquilo que alguns autores chamam de trabalho de fronteira (Gieryn, 1983), que nada mais é senão um esforço discursivo, por parte das chamadas ciências naturais (e das instituições que as sustentam), para delinear a separação entre o tipo de conhecimento produzido pela ciência e o de outras formas estabelecidas de saber. Esse trabalho baseia-se na ideia, autoproclamada e difundida de dentro para fora da comunidade científica (Mitroff, 1974), de que o conhecimento científico seria uma forma de saber obtida através do contato direto com a natureza e, por isso, possuiria valor e qualidade menos vulneráveis a controvérsias e disputas com outras áreas do saber. O principal objetivo do trabalho de fronteira é o de garantir uma aura de isenção para o saber científico e buscar imunizá-lo contra críticas vindas de outras áreas do conhecimento, qualificadas como não científicas. Sob esse aspecto, o objetivo final desse esforço discursivo seria o de dar mais crédito aos centros de produção dessa forma de conhecimento, classificando-os como locais de conhecimento puro e nos quais, portanto, dúvidas acerca de políticas públicas, por exemplo, poderiam ser dirimidas. Para poder valer-se desse discurso, uma instituição deve empenhar-se na construção dessas fronteiras, garantindo visibilidade a seus membros e associados, além de posição política de destaque dentre outras instituições de saber. 
O trabalho de fronteira, portanto, foi tarefa fundamental nos primeiros anos da Escola Politécnica de São Paulo. A divulgação da produção dos politécnicos tinha a clara intenção de aliar o discurso da escola àqueles de progresso e modernidade. Essa união entre a ideia de ciência e progresso é algo recorrente no processo de afirmação da ciência como meio para o desenvolvimento (Mulkay, 1976, p.75). Essa 'estratégia' se vale da difusão da ideia de progresso contínuo e cumulativo da ciência, ou seja, a ideia de que a ciência, através da coleta e interpretação de dados da natureza, é capaz de levar ao domínio das forças naturais e, como consequência, ao progresso da humanidade. Além disso, a difusão desse saber faz parte da construção desse progresso, daí a afirmação inicial da Revista convocando todos os que lutam tanto "pelo saber como pelo ensino" (Albuquerque, nov. 1904, p.4), ou seja, na difusão de um saber que não tem outro interesse que não seja o próprio saber.

Essa aparente contradição entre a ideia de conhecimento prático e a própria ideia da ciência era maquiada pelo discurso da modernidade, que colocava o saber científico como a principal força motriz da tecnologia. Os artigos da Revista Politécnica demonstravam claramente a preocupação de 'unir' esses estudos teóricos e logo os transformar em aplicação prática. $\mathrm{Na}$ passagem do discurso teórico para o discurso prático é que se encontram as principais tendências ideológicas e as formas e estratégias de difusão e validação do conhecimento científico. Essas estratégias necessitam estar baseadas no trabalho de fronteira, como forma de garantir que o discurso da ciência seja considerado a respeito da realidade natural, capaz de transformar o mundo.

A escola científica, penetrando vitoriosa no trabalho ininterrupto em busca da verdade, veio animar os operários do intelectual, encaminhando-os suavemente para o campo da experiência e observação, indubitavelmente as únicas fontes em que é dado colher os elementos necessários ao aperfeiçoamento da espécie e do meio (Gama, jan. 1905, p.118).

Esse aperfeiçoamento manifestava-se, por exemplo, em artigos sobre as pontes da cidade (Rodrigues, abr. 1905) e as formas com que as construções deveriam ser feitas, a importância da estrada de rodagem e da difusão do automóvel (Souza, jun.-jul. 1905), o papel da eletricidade em São Paulo (Ramos, dez. 1905), ou debates envolvendo qual o melhor modo de captar água potável para o abastecimento do município (Leme, jan. 1906), ou modelos de beleza e funcionalidade para as estações de trem (Pujol Jr., jun.-ago. 1908). Essas propostas de intervenção, que com o passar dos anos aumentam em número e em variedade de temas, são o reflexo da crescente importância da Escola Politécnica na vida política do estado de São Paulo, bem como o resultado efetivo do trabalho de fronteira realizado pela instituição.

O resultado desse processo foi transformar uma instituição vista antes com desconfiança por parte das elites políticas paulistas num centro de apoio a algumas decisões conturbadas para a vida da capital e do estado, como foi o caso do abastecimento de água no município de São Paulo (Vargas, 1994b, p.191-197), ou à validação de determinadas políticas públicas que sofriam oposição de setores da mesma elite ou de parte da rarefeita opinião pública paulista. A conquista desse espaço na vida da cidade e do estado seguiu algumas estratégias que são comuns no processo de validação do conhecimento científico desde o século XVIII. O primeiro passo foi a criação de público específico para o saber que a ciência se propõe a divulgar; daí a importância da publicação e, principalmente, de sua estratégia editorial, já 
que a quase inexistência de público que apreciasse os assuntos abordados na escola tornava necessária a divulgação de textos com pouco ou nenhum conteúdo propriamente científico.

O que fortalece uma instituição como representante de determinado tipo de saber é sua capacidade de utilizar aquilo que o historiador da ciência Steven Shapin (1984, p.483) chamou de multiplicação de testemunhas. Esse conceito se baseia no pressuposto de que a produção do saber científico só é validada se aquele determinado conhecimento for socialmente aceito, ou seja, se um conjunto significativo de membros da sociedade concordar com determinadas formas de conhecimento. A ciência, por se afirmar como forma de saber diversificado, que na visão dos cientistas se apoia em suposta experiência de observação 'direta' da natureza, é apresentada como portadora de verdades acerca do mundo natural. Essas verdades baseiam-se em afirmações que, calcadas em dados e observações, dificilmente poderiam ser questionadas em sua essência; se transformariam, portanto, naquilo que em língua inglesa é conhecido como matters of fact, verdades de fato, em tradução livre (Schaffer, Shapin, 1985, p.3-21).

A construção dessas verdades de fato está calcada em três 'tecnologias' que têm como principal objetivo a multiplicação de testemunhas e são divididas em material, literária e social (Shapin, 1984, p.484). Cada uma dessas tecnologias visa garantir que a produção do conhecimento científico seja amplamente aceita e difundida e que as unidades que produzem esse tipo de saber sejam entendidas, antes de tudo, como centros produtores de verdades acerca do mundo natural.

Por tecnologia material entendem-se a construção e a operação de máquinas diversas que fazem o levantamento de dados e servem como intermediárias entre o homem e o mundo natural; são, portanto, o que Bruno Latour e Stephen Woolgar (1997) chamam de informantes. O papel desses informantes, no entanto, vai além da produção de dados que servem de base para o conhecimento científico. Na realidade, eles são as tecnologias básicas para a produção de verdades de fato, pois, sendo base material dos experimentos e gerando dados, eles também são peças fundamentais para a produção de imagens e de literatura que servirão para a multiplicação das testemunhas.

Numa instituição científica, as máquinas ocupam papel central. Boa parte dos esforços iniciais da Escola Politécnica esteve concentrada na aquisição de máquinas e no desenvolvimento de laboratórios que pudessem dar conta da produção de saber necessária à sobrevivência da instituição. Os dois grandes feitos da escola, que valeram sua transformação numa das grandes instituições do estado de São Paulo ao longo da Primeira República, foram a construção do Gabinete de Resistência dos Materiais (GRM), em 1904, e a criação do Laboratório de Eletrotécnica, em 1911.

O GRM, como era mais usualmente referido, constituiu o grande trunfo dos primeiros anos da escola. Foi projetado pelo professor Ludwig von Tetmayer, da Escola Politécnica de Zurique, que nele trabalhou a pedido de Paula Souza. Além disso, o professor indicou como responsável pela operação do GRM seu assistente, William Fischer, que permaneceu na instituição até 1906 (Nagamini, 2004, p.208). Nesse período, o GRM transformou-se no núcleo da instituição, sendo o centro da principal polêmica em que a Escola Politécnica se envolveu nos primeiros anos do século passado e que acabou por opor a instituição paulista a suas congêneres na capital da República. 
O Laboratório de Eletrotécnica, por sua vez, resultou de parceira entre a Escola Politécnica e a Light \& Power Co., servindo de exemplo para as relações entre a pesquisa realizada na escola e a municipalidade, já que a estruturação do laboratório só foi possível graças à doação pela empresa, representada por seu engenheiro-chefe, Robert C. Brown, de um reator, e ao fornecimento gratuito de eletricidade, recebendo em troca um centro de treinamento de mão de obra para a empresa, além de valiosas contribuições para os interesses da Light na cidade, sobretudo nos casos da substituição da iluminação a gás pela elétrica e da construção de grandes barragens (Sávio, 2010, p.84-89).

De que forma então essas três tecnologias funcionavam para a multiplicação de testemunhas? No caso da tecnologia material, o ponto central é a ideia de replicação, ou seja, de reprodução das condições materiais para a produção da ciência. Além disso, esses informantes são peças importantes para a produção de iconografia, o que, por sua vez, é peça fundamental para a criação de uma imagem de ciência para a sociedade, bem como para o discurso do progresso no qual ela está inserida. Ao observar esse período, nota-se que são raros os números da Revista Politécnica sem algum tipo de produção iconográfica. Boa parte dessa produção iconográfica veiculada nas páginas da publicação era ilustrativa da própria instituição: fotos de alunos e professores, de equipamentos, projetos ou mesmo das instalações da escola.

O prédio da Escola Politécnica é, aliás, uma das tecnologias materiais que mais foram abordadas pela Revista ao longo desse período. Gravuras ou fotos do prédio ou de seus recintos eram uma constante. Na edição comemorativa do primeiro aniversário da Revista (fev. 1905), que abre com uma foto de Paula Souza, há abundância de material iconográfico da escola e de suas instalações, que eram, no momento, o que de mais avançado uma instituição de ciência possuía no estado, entre elas a estrela de primeira grandeza: o Gabinete de Resistência dos Materiais. A razão para esse destaque está no fato de, na época, o GRM ter lançado sua primeira grande publicação, o Manual de resistência dos materiais, que se transformou no grande trunfo para atestar à instituição a respeitabilidade que tanto procurava.

Paralela a essa tecnologia material, estava a tecnologia literária, papel que cabia à Revista e a sua estratégia editorial de se dedicar não apenas a questões relativas à vida acadêmica ou puramente científica, mas de tornar acessível ao leitor não iniciado em matéria de ciência parte de seu material. Estratégia, aliás, em consonância com as tecnologias sociais empregadas pela instituição, ou seja, a procura das testemunhas corretas que pudessem amparar a escola e seus projetos.

A publicação da Revista Politécnica era responsabilidade dos estudantes que, entretanto, não precisavam desembolsar qualquer quantia. Graças a um acordo entre o Grêmio Politécnico e o governo do estado, a Revista era impressa, sem qualquer custo para a instituição, nas gráficas da tipografia do Diário Oficial. Isso era uma garantia para a periodicidade da Revista, além de cooperar enormemente com a estratégia editorial dos politécnicos. Em razão desse arranjo, os estudantes da Escola Politécnica podiam distribuir gratuitamente os cerca de quinhentos exemplares de cada edição para as pessoas certas, garantindo que se encontrasse entre elas o apoio para o projeto representado pela escola. O principal para a aceitação da ciência é a qualidade das testemunhas (Schaffer, Shapin, 1985, p.39). Pouco adiantaria para 
uma instituição que nasceu sob o signo da desconfiança angariar testemunhas que fossem bons cientistas, engenheiros ou tecnólogos, mas com pouca ou nenhuma influência política.

Essa característica do trabalho de fronteira é de fundamental importância para se compreender o papel institucional da produção do saber, principalmente quando se observam o clima político e intelectual da Primeira República e a forma como as instituições serviam aos interesses de uma pequena elite. É essencial compreender as formas pelas quais determinadas instituições gozam de mais atenção das instâncias decisórias do Estado do que outras. Além disso, é preciso lembrar que a Escola Politécnica servia sobretudo a uma clientela elitizada, formada em boa parte de filhos de abastados produtores de café, grandes comerciantes e de alguns poucos estudantes oriundos das classes liberais. Prova disso está em alguns dos nomes que passaram pela escola, como seus professores ou alunos: Antônio Francisco de Paula Souza, Luiz Anhaia Melo, Francisco de Paula Ramos de Azevedo, Armando Salles e Roberto Simonsen, entre tantos outros.

O papel empreendido pela Revista Politécnica foi de grande importância para a afirmação regional da escola, sendo fundamental na criação de uma aura de isenção para a instituição. No entanto, a grande batalha travada pelos politécnicos e que serviu de instrumento precioso para a afirmação da escola e de seus projetos estava ligada à primeira publicação dos estudantes, o Manual de resistência dos materiais, no entender da instituição paulista, o primeiro grande trabalho científico de 'aplicação prática' feito por uma instituição científica nacional. A edição do Manual representou o primeiro grande embate dos politécnicos fora das fronteiras do estado de São Paulo.

\section{A prova de fogo: o imbróglio do Manual de resistência dos materiais}

Maior triunfo da instituição, o Manual de resistência dos materiais foi também seu maior problema. Fato é que a publicação apareceu como prova da eficácia da Politécnica e da pertinência de uma instituição do gênero em São Paulo. Uma disputa entre os professores e alunos da Politécnica de São Paulo e alguns professores da Escola de Engenharia do Rio de Janeiro e do Instituto Politécnico Brasileiro transformou, no entanto, aquela que seria, segundo seus autores, a maior publicação da área no Brasil em um problema interinstitucional.

A história começa com a criação do GRM, em 1899. O grande gasto com o laboratório já tinha em vista sua aplicação prática, que era a publicação de um manual de resistência que abrangesse boa parcela dos produtos utilizados em construções no Brasil. Seria um trabalho de grande importância para a engenharia nacional, bem como para a própria instituição. Sob a direção de William Fischer, auxiliado pelo então aluno Hipólito Gustavo Pujol Jr., foram elaboradas séries de experimentos envolvendo os mais diversos materiais usados na construção civil e em várias outras áreas: "95 amostras de madeiras; cinco amostras de metais produzidos no país; cal, procedente de cinco fábricas; concreto e o primeiro cimento nacional, da marca Rodovalho, além de quinze marcas importadas" (Nagamini, 2004, p.208), numa análise que ocupava a maior parte do trabalho. Essas experiências tinham como objetivo principal definir a resistência desses materiais, a relação peso/volume, sua melhor forma de preparo e sua aplicação nas áreas da construção. 
Esse esforço resultou na publicação do Manual de resistência dos materiais, em 1905, considerado uma grande vitória pela Escola Politécnica. Ele representava a prova cabal de que a instituição tinha papel importante para o progresso da nação, além de contribuir para questões imediatas que afligiam os engenheiros. Foram enviadas cópias do Manual a diversas instituições do país, incluindo o Instituto Politécnico Brasileiro e o Clube de Engenharia, com o intuito de propagandear o feito e, principalmente, conseguir o respaldo de seus pares. Aos congêneres cariocas foi requerida ainda a produção de pareceres com o objetivo de endossar a qualidade do trabalho.

O objetivo dos alunos da Escola Politécnica era produzir uma obra que oferecesse algumas informações acerca da segurança e da durabilidade dos materiais aplicados às diversas áreas da indústria e da construção, bem como acerca de sua economia. Entretanto, o grande trabalho produzido pela escola logo se transformou numa contenda acerca das abordagens e dos cálculos que constavam no Manual. Alguns comentários de professores e, sobretudo, de membros do Clube de Engenharia do Rio de Janeiro, demonstravam que certas apresentações, em especial aquelas sobre a resistência da madeira e o preparo do cimento, estavam incorretas, o que colocava em dúvida o trabalho no qual os alunos e professores da instituição paulista tinham dedicado tanto tempo e energia.

O Manual foi analisado por importantes nomes do Clube de Engenharia, como os engenheiros Gabriel Osório Almeida e Carlos Euller. Pelo lado do Instituto Politécnico Brasileiro, a mais longa e detalhada análise é do engenheiro F. Cabrita. Apesar de ambos os pareceres contestarem o discurso apregoado pelos alunos e professores da Escola Politécnica de São Paulo, o mais incisivo e desafiador foi o oferecido pelo Clube de Engenharia, em seus dois principais questionamentos. Seus responsáveis ativeram-se a questões relativas à organização e aos cálculos oferecidos pelo Manual, apontando alguns problemas que poderiam causar confusões e levar a erros que comprometeriam o trabalho de um profissional. A argumentação de Osório de Almeida não atacou nenhum ponto referente aos cálculos, nem contestou os resultados; criticou, porém, a organização e a forma de apresentação dos cálculos e das tabelas ao longo da obra. Segundo Osório, a ausência de cálculos específicos, principalmente aqueles referentes ao ponto inicial de ruptura, comprometiam o trabalho do engenheiro naquilo que ele tinha de prático. De acordo com suas observações, a ausência do coeficiente de ruptura inicial e a apresentação apenas do coeficiente final de ruptura dos materiais, em especial da madeira, levavam a cálculos incorretos acerca do peso máximo suportado pelos materiais individualmente analisados. Constatando essa falha, o engenheiro pede a completa reformulação das tabelas, apontando problemas acerca do método de apresentação.

A avaliação do engenheiro Carlos Euller é muito mais severa, apontando, entre outras falhas, algumas de cálculo quanto aos experimentos realizados nas dependências do GRM. Se fosse confirmada a argumentação de Euller, todo o trabalho da Escola Politécnica seria colocado em xeque - devido aos vultosos investimentos feitos no GRM -, havendo o risco de as velhas críticas, quanto à fundação de tal instituição em São Paulo, voltarem a ganhar força.

A posição ocupada por Euller na capital federal - engenheiro e diretor dos laboratórios da Estrada de Ferro Central - dava a suas opiniões peso e caráter mais importantes. Ao contrário de Osório ou Cabrita, Euller centra fogo na metodologia de análise e nos parâmetros usados para o preparo da experiência, argumentando que no trabalho cotidiano do engenheiro, 
tais medidas ou formas de preparo para a utilização dos materiais eram diferentes daqueles apresentados pelos politécnicos de São Paulo. Na realidade, o engenheiro carioca apresentava como argumentação um clássico problema relativo à replicação do experimento: é possível ou não reproduzir um determinado experimento em tempo e condições diversos? (Franklin, 1989, p.147-164).

No que diz respeito à questão da padronização do experimento, demonstrada pelo engenheiro carioca através da explanação da forma como são feitos os preparos de briquetes de concreto nos laboratórios da Estrada de Ferro, em oposição à forma adotada pelos alunos da Escola Politécnica de São Paulo, as queixas de Euller (dez. 1905, p.134) são claras quando afirma que "seria conveniente que as grandes administrações do Estado e particulares conviessem em fixar normas certas para estes ensaios, a fim de torná-los comparáveis entre si". Tratando-se de questão específica para os experimentos de resistência, isso significava duro golpe para aquele que seria o principal objetivo da obra: auxiliar o trabalho prático do engenheiro. Essa argumentação ia ao encontro das críticas usualmente feitas pelos detratores da escola. Os questionamentos de Euller, portanto, poderiam servir de munição para uma nova carga retórica contra a Politécnica, que reviveria argumentos como aqueles utilizados por Euclides da Cunha a favor dos institutos.

Além disso, Euller reforça sua argumentação atacando um ponto mais sensível, que diz respeito ao uso da fórmula para a determinação dos pontos de ruptura inicial e final da madeira, assunto que ocupa a maior parte do trabalho do Manual de resistência dos materiais e que, portanto, é fundamental para a integridade e validade de toda a obra. Euller chama a atenção para aquilo que seria um erro teórico no cálculo e para o mau uso da fórmula para determinar o ponto de ruptura das madeiras. Em suas palavras: "Com referência à tração, a fórmula $\mathrm{T}=\frac{\mathrm{Me}}{\mathrm{I}}$, de que serviram para determinar o coeficiente de ruptura desse modo de trabalho, dá o mesmo valor para este e para a compressão; ora, é sabido que as madeiras resistem menos à compressão do que à tração e que é sensível a diferença entre os dois coeficientes" (Euller, dez. 1905, p.134).

O engenheiro ainda aponta que faltou aos estudantes que participaram da confecção dos experimentos no GRM levar em conta a não homogeneidade da madeira, adotando para tanto uma variável estatística (Timoshenko, Young, 1965) a fim de cobrir as variações naturais dos diversos tipos de madeiras utilizados na construção. Se a análise do engenheiro carioca estivesse correta, todos os cálculos adotados então pelo Manual teriam de ser revistos. E, pior de tudo, a revisão teria de ocorrer pelo fato de os estudantes terem aplicado o que pede a 'teoria', deixando de lado a 'prática' do dia a dia do engenheiro.

Por fim, a análise do engenheiro F. Cabrita, do Instituto Politécnico Brasileiro, critica aquilo que os politécnicos de São Paulo consideraram um feito inédito. Cabrita contesta o ineditismo do Manual ao chamar a atenção para a vasta produção bibliográfica feita ao longo do século XIX, por engenheiros ligados à Academia Real Militar, até os mais recentes pertencentes ao Instituto Politécnico Brasileiro. A apresentação desse panorama histórico minava o discurso de pioneirismo dos politécnicos paulistas e chamava a atenção para uma longa tradição da engenharia brasileira no século XIX, valendo-se sobretudo da figura mítica de André Rebouças. Famoso engenheiro brasileiro, mulato e engajado numa cruzada modernizadora no Brasil, 
Rebouças era o símbolo de um projeto parcialmente antagônico àquele representado pela Escola Politécnica de São Paulo e pela política paulista como um todo.

Em suas considerações, Cabrita apresenta longa série de experimentos realizada por André Rebouças, resultando em publicações que incluem coeficientes e tabelas, envolvendo experiências com cimento Portland e, indo além dos politécnicos, comparando seus experimentos com outros realizados em países como Inglaterra e França. No caso específico das madeiras, Rebouças testou espécies de várias origens com os respectivos coeficientes de ruptura. Essa argumentação lançava luz sobre outro projeto de modernização que, até então, dera conta das necessidades encampadas pelo Império e pela nascente República (Schwartzman, 2001; Carvalho, 1998).

Além deles, são listados Pedro Alcântara Bellegarde, Antônio Manoel de Mello e Guilherme Schuch, como pioneiros no desenvolvimento de trabalhos sobre resistência dos materiais e que foram esquecidos nas menções feitas pelos paulistas. Outro exemplo lembrado foi o trabalho de Del Vecchio, de 1883, publicado sob o título de Estudos sobre materiais de construção, em que o autor, segundo Cabrita (abr. 1905, p.138-139), estuda 108 madeiras diversas, nacionais, além de sete variedades de granitos, cujos resultados são reunidos num quadro sintético que abrange todo o trabalho. Após a longa e minuciosa explicação Cabrita (p.140) conclui com ironia:

Já vai, porém, por demais longa esta demonstração de que 'o primeiro passo' na longa e penosa tarefa do conhecimento dos nossos materiais de construção não foi dado pelo 'Grêmio Politécnico de São Paulo'. E que, também, comparável o trabalho do Grêmio, não há somente o do Professor Emilio Palacio, de Buenos Aires. Antes dos distintos acadêmicos, tiveram os nossos materiais de construção vários outros experimentadores, - todos, membros deste ilustre Instituto, em cuja Revista registraram o resultado de suas conscienciosas, pacientes e múltiplas observações.

A conclusão de Cabrita, ainda ironizando o que os politécnicos de São Paulo julgavam matéria "quase ainda inexplorada entre nós" (p.140) é um duro golpe no discurso da instituição de São Paulo e uma vitória para a tradição do Instituto Politécnico do Rio de Janeiro, reservando para si o direito de reivindicar pioneirismo em matéria de engenharias no Brasil.

Diante das críticas que surgiram ao redor da publicação, distribuída pelos politécnicos na esperança de obtenção de reconhecimento incondicional de seus congêneres no país, gerouse a necessidade de resposta firme dos membros do grêmio. Com apoio de seus professores e uso dos recursos da instituição, a resposta precisava estar à altura dos argumentos utilizados pelos comentadores. Havia muito em jogo, principalmente o nome de professores e o prestígio da instituição no cenário nacional, o que poderia garantir sua sobrevivência a longo prazo. Para tanto, toda a discussão foi apresentada e publicada num só número da Revista Politécnica, lançado logo após a publicação do Manual. A estratégia casava-se, de um lado, com a necessidade de defender os pesados investimentos no GRM e justificar a existência da instituição, e, de outro, com a preservação dos nomes dos alunos e professores envolvidos na produção da obra e de seu discurso.

O eleito para preparar a resposta foi Hipólito Gustavo Pujol Jr. Ao longo de duas semanas, Pujol Jr., com a ajuda de seus professores, preparou longa defesa do Manual, apontando uma a uma suas virtudes e aquilo que considerava um despropósito de alguns de seus detratores. 
A resposta de Pujol Jr. ocorreu numa concorrida sessão do Grêmio Politécnico. A apresentação dividiu-se em duas partes, com atenção especial, como não poderia ser diferente, aos ataques realizados por Carlos Euller. As afirmações de F. Cabrita acerca do não ineditismo do Manual ficaram fora da resposta dos politécnicos de São Paulo, talvez por falta de argumentos.

Pujol Jr. inicia sua intervenção com um discurso de louvor ao Manual de resistência dos materiais, que, em sua opinião, lograra grande sucesso. Em seguida, o estudante chama a atenção para a importância das críticas recebidas e o modo como auxiliariam no desenvolvimento de novas pesquisas no GRM e em toda a instituição paulista. Feitas as apresentações de praxe, Pujol Jr. inicia longa, e muitas vezes agressiva, dissertação. A estratégia adotada pelo aluno prodígio da Politécnica procurava valorizar o trabalho por eles realizado, evitando que as críticas ecoassem além dos limites da instituição. A dissertação inicia-se com a abordagem das tabelas e daquilo que o engenheiro Osório de Almeida apontou como sendo uma falha perigosa da obra: a ausência dos coeficientes iniciais de ruptura. Pujol Jr. argumenta que, antes de aquilo se caracterizar como falha, fora escolha dos organizadores do Manual, que optaram por uma metodologia na construção das tabelas que resultou na ausência do coeficiente reclamado pelo engenheiro carioca. Observação mais atenta, no entanto, esclareceria que a ausência desse coeficiente nas tabelas referia-se ao método de exposição e à busca de clareza. Para os membros do Grêmio Politécnico, tratava-se de escolha metodológica justificada, já que seriam: "apenas os coeficientes de ruptura completa, únicos, a nosso ver, em que se pode fundar um critério seguro de cálculo de uma construção, procurando-se nos coeficientes de primeira fenda, apenas um elemento auxiliar do julgamento do material que se considera" (Pujol Jr., abr. 1905, p.151).

Diante, porém, da argumentação de Osório de que a ausência dessas informações comprometeria o cálculo geral da aplicação desses materiais, os membros do grêmio admitem, em edições seguintes, aplicar os novos coeficientes. Feito esse reparo, Pujol Jr. segue em frente para abordar o mais grave dos ataques contra a publicação, já que além de atentarem para falhas na metodologia de apresentação, as críticas sugerem problemas na abordagem teórica e deficiência no uso dos cálculos para o trato de certos materiais. Essas afirmações, feitas por Carlos Euller, ganhavam mais força pelo fato de o autor ser o responsável pelo Laboratório de Resistência dos Materiais da Estrada de Ferro Central. No caso de Euller, a resposta capitaneada pelo politécnico tinha de ser à altura dos ataques, e não deixar sombra de dúvidas acerca da qualidade da publicação do grêmio.

O primeiro ataque de Euller recai sobre o trabalho com a produção de briquetes de concreto para a análise no GRM. Lembrando a argumentação do engenheiro, havia problemas de padronização na produção dos materiais e problemas de cálculo na análise dos experimentos. Na resposta do presidente do Grêmio Politécnico, em vez de atacar diretamente as afirmações de Euller, procura-se demonstrar a natureza diversa dos experimentos, o que validaria métodos e resultados distintos. Enquanto os experimentos do GRM seguem regras chamadas por eles de convencionais, ou seja, com base em métodos genéricos, aqueles realizados por Euller seriam específicos para aplicação na ferrovia. Em outras palavras, a argumentação é a de um experimento de caráter universal contra um experimento de caráter particular. "Muito maior importância deve, porém, ser atribuída às experiências convencionais, tais como as realizou a Comissão do Grêmio, cujos resultados são inteiramente gerais, aproveitando a todos 
indistintamente e apresentando inestimável vantagem de uma perfeita comparabilidade das experiências congêneres estrangeiras" (Pujol Jr., abr. 1905, p.157).

A abordagem do problema, apresentada pelos alunos da escola, aponta para um dos argumentos de Euller, que era o da falta de padronização dos experimentos para os briquetes. Pujol Jr., dessa forma, procurava apontar o desconhecimento de Euller acerca da padronização dos experimentos por eles utilizada, ao mesmo tempo em que o desqualificava duplamente: como cientista e como erudito. $\mathrm{O}$ discurso segue nesse sentido, procurando afirmar que a argumentação do oponente era, em muitos sentidos, descabida, já que o engenheiro carioca afirma obter resultados diferentes com processos diferentes, o que dá ao futuro engenheiro paulista ensejo para chamar a atenção quanto à existência de uma padronização, "as normas prescritas pela Associação Internacional para o Ensaio de Materiais, cujas indicações foram seguidas pelo Grêmio" (Pujol Jr., abr. 1905, p.159).

A argumentação segue envolvendo ainda mais o clássico problema da replicação: não haveria a possibilidade de que os briquetes resultassem iguais graças a fatores fora do controle do experimento do GRM, entre eles o clima, a pressão e a água, diversos em cada um dos locais, influenciando os processos químicos que resultam da produção do concreto. Dessa forma, completa Pujol Jr., o Manual cumpre sua função ao demonstrar quais das marcas disponíveis no mercado nacional são as melhores no que tange à resistência.

Após essa argumentação, o jovem estudante segue para o ponto fulcral indicado por Euller e o mais sensível para todo o problema desencadeado por suas afirmações, mostrando uma falha de cálculo relativa aos coeficientes de extensão de madeiras, obtida por experimentos de tração e compressão. A argumentação dos politécnicos de São Paulo procura responder ao apontamento do engenheiro carioca a partir da demonstração do cálculo aplicado às madeiras nos experimentos de tração e nos de compressão. A explanação dos membros do Grêmio Politécnico sinaliza a utilização distinta dos valores de tensão, afirmando:

Em cada instante da experiência essa fórmula fornece valores $-\mathrm{T}$ e $+\mathrm{T}$, efetivamente iguais para o 'esforço específico de compressão' desenvolvido nas fibras mais fatigadas da semiseção superior e para o 'esforço específico de extensão' desenvolvido nas fibras mais fatigadas da semiseção inferior. No instante da fratura da viga, porém, que se manifesta pela ruptura do feixe de fibras distendidas, o valor de $\mathrm{T}$, dado por essa fórmula para o trabalho das fibras mais fatigadas, igual embora para ambas as semiseções, representa a 'resistência da madeira à extensão', pois mede a intensidade da tração que produz a ruptura do feixe de fibras mais fatigadas da parte inferior da peça flexionada. Esse valor de T, no mesmo instante, representa também o 'esforço específicio de compressão' desenvolvido nas fibras mais fatigadas da parte superior da vigota, mas como essas fibras não se rompem no momento da fratura da peça por flexão, é evidente que tal esforço não representa a 'resistência da madeira à compressão' (Pujol Jr., abr. 1905, p.162).

A conclusão da explanação é a de que a fórmula aplicada pelos politécnicos de São Paulo não gera valores iguais para coeficientes diferentes, variando, portanto, de acordo com as expressões de compressão e extensão. Nesse sentido, a resposta da escola paulista é correta. O problema apontado por Euller, no entanto - a ausência de uma variável estatística que abarcasse a heterogeneidade dos materiais estudados -, permanece sem resposta. O que se provou com a argumentação de Pujol Jr. foi a validade do cálculo e não sua aplicabilidade a 
questões cotidianas. Transparece nas palavras do politécnico uma argumentação com base no aprendizado teórico desenvolvido no GRM, mas não sua aplicabilidade na vida prática do engenheiro, a pedra angular da argumentação a favor da Escola Politécnica de São Paulo, ou seja, exatamente o oposto do argumento usado para a defesa da Escola Politécnica contra seus detratores em São Paulo: o 'saber prático'.

Pujol Jr. termina o discurso de forma agressiva, apontando que a argumentação de Euller era descabida, já que os cálculos, provados pela explanação e pela apresentação de longas séries de experimentos desenvolvidos ao longo da construção do Manual e apresentados na publicação, pareciam, naquele momento, irrefutáveis. A conclusão, novamente, beira os limites da boa educação.

Não sabemos o que mais estranhar em tudo quanto acabamos de longamente examinar, se a simplicidade com que o engenheiro Carlos Euler afirma ao Clube de Engenharia o que, em relação ao Manual vimos se revelar inteiramente falso, ou se a facilidade com que esta ilustrada corporação, que todos nos habituamos a acatar, funda uma parte do seu parecer, na opinião confusa e capciosa daquele engenheiro... E, como única explicação, preferimos, para que não se torne antipática a nossa atitude nesta refutação, levar tudo isso à conta de engano ou descuido, ainda que tal pareça pouco provável, diante do apuro com que parece ter sido redigido e revisto o parecer em questão, que nos chega às mãos nitidamente impresso à máquina, em papel rubricado a cada página, conferido a cada passo sob o autógrafo de mais de um membro da Diretoria do Clube (Pujol Jr., abr. 1905, p.165).

Pujol Jr. deixa claro o que estava em jogo: não o trabalho de alguns estudantes e professores da Escola Politécnica, mas sim a reputação de uma instituição recém-criada e sua afirmação perante outras, já consolidadas e respeitadas. Em última instância representava formas distintas de expressão política e de ideias acerca de como organizar e modernizar a nação. Sob essa perspectiva, a Escola Politécnica de São Paulo deveria representar o futuro, enquanto as instituições fundadas no Império e seus defensores, entre eles Euclides da Cunha, representariam o passado a ser superado. A missão havia sido cumprida em parte, mas era o que importava aos politécnicos.

\section{Considerações finais}

A importância do episódio aqui analisado está exatamente no papel institucional que a ciência assumiu no Brasil ao longo do século XX e no papel de destaque adquirido pelas instituições de ciência como agentes políticos. Essa percepção é evidenciada quando se observa o nascimento dessas instituições e os diversos desafios e tensões que tiveram que enfrentar até sua aceitação pelas elites políticas. A Escola Politécnica de São Paulo formou-se dentro desse complexo processo de combates, transformando-se, com o passar dos anos, em um dos principais alicerces para a validação de políticas públicas no estado de São Paulo.

Os combates travados para a construção de uma instituição científica, no entanto, não se expressam apenas por seus problemas políticos ou nas demandas relativas à obtenção de recursos, mas sim através das contendas e disputas científicas nas quais ele se insere e na forma 
como essa disputas são tornadas públicas aos diversos membros envolvidos na construção institucional, sejam eles cientistas ou não.

O meio mais importante para a consolidação institucional foi, portanto, a divulgação científica, e a Revista Politécnica, a principal arma nas guerras para a consolidação da instituição. A prova cabal disso, e do sucesso dessa empreitada, foi a transformação da Revista no órgão oficial da instituição nos anos 1950. Essa transformação mostra a importância do órgão na construção da imagem da instituição perante o público e na forma como se tornou porta-voz de uma ideia de ciência que aprimorou-se e profissionalizou-se ao longo dos anos.

Esse processo de institucionalização da ciência nos possibilita compreender que a divulgação científica não apenas valida determinadas formas de saber, mas também autoriza determinadas instituições e seus meios de divulgação a transformarem-se em portadores autorizados desse saber (Collins, 1999). Na história da ciência em São Paulo a Escola Politécnica tornou-se vedete graças à eficiente propaganda, realizada em seus primórdios pela Revista Politécnica e às guerras travadas por seus membros para mostrar que a instituição era a grande portadora de um saber 'prático', não meramente teórico, e que respondia ao discurso dominante entre as elites paulistas de então.

Nesse sentido, é fundamental estudar os caminhos traçados para a institucionalização do saber científico, a fim de compreender aqueles que o desenvolvimento da ciência seguiu no Brasil. A história da Escola Politécnica de São Paulo é um grande exemplo de como uma instituição contestada em seus primórdios conseguiu garantir sua existência, o que quer dizer verbas e apoio político para sua expansão, numa sociedade em que a ideia de ciência estava muito distante do dia a dia dos laboratórios.

As instituições possuem um caráter político, que se expressa de formas diversas em diferentes momentos da história. Seja como validadora de políticas públicas ou de discursos sobre a forma de organização político-social do país (o que se encaixa muito bem na retórica de superioridade paulista ao longo da Primeira República), a compreensão de instituições como a Escola Politécnica de São Paulo vai muito além da ciência.

\section{AGRADECIMENTO}

Ao professor João Carlos Moreira (Faculdade de Ciências Integradas do Pontal/Universidade Federal de Uberlândia) pelo auxílio no entendimento das equações sobre os coeficientes de compressão e extensão.

\section{NOTA}

${ }^{1}$ As matérias publicadas nos primeiros anos da Revista (do número 1 ao 59), divididas por assuntos e com as quantidades correspondentes, são: agricultura (seis); álgebra (15); arquitetura (dez); aviação e estradas de ferro (17); biografias (12); combustíveis (uma); comentários diversos (oito); concreto (13); construções (11); desenho geométrico (16); didática (uma); economia e política (quatro); eletricidade (17); estabilidade (sete); estatística (uma); estradas de rodagem (quatro); exposições (uma); física (duas); geodésia, astronomia e topografia (21); laboratórios e oficinas (três); literatura (duas); máquinas (16); mecânica (dez); metalografia (cinco); meteorologia (uma); minas e metalurgia (cinco); mineralogia (duas); pontes e estradas (14); processo de medidas (seis); química em geral (nove); resumos de conferências, nacionais e estrangeiras (30); siderurgia (duas); termodinâmica (três). 


\section{REFERÊNCIAS}

ALBUQUERQUE, Alex.

Apresentação da revista. Revista Politécnica, São Paulo, n.1, p.3-4. nov. 1904.

BARNES, Barry; BLOOR, David; HENRY, John. Scientific knowledge: a sociological analysis. London: Athlone Press. 1996.

BLOOR, David.

Polyhedra and the abominations of Leviticus. The Journal for the History of Science, Cambridge, v.11, n.39, p.245-272. 1978.

CABRITA, F.

Parecer do Instituto Politécnico Brasileiro. Revista Politécnica, São Paulo, n.4, p.135-147. abr. 1905,

CARVALHO, José Murilo de.

A formação das almas: o imaginário da República no Brasil. São Paulo: Companhia das Letras. 1998.

COLLINS, Henry M.

Tantalus and the aliens: publications, audiences and the search for gravitational waves. Social studies of science, London, v.29, n.2, p.163-197. 1999.

EULLER, Carlos.

Carta de Carlos Euller. Revista Politécnica, São Paulo, n.9, p.133-135. dez. 1905.

FRANKLIN, Allan.

The neglect of experiment. Cambridge: Cambridge University Press. 1989.

GAMA, Saldanha da.

Notas. Revista Politécnica, São Paulo, n.2, p.118. jan. 1905.

\section{GIERYN, Thomas. F.}

Boundary-work and the demarcation of science from non-science: strains and interests in professional ideologies of scientists. American sociological review, Nashville, v.48, n.6, p.781-795. 1983.

LATOUR, Bruno; WOOLGAR, Steve.

$A$ vida de laboratório: a produção dos fatos científicos. Rio de Janeiro: Relume Dumará. 1997.

LEME, Betim Paes.

O abastecimento de águas na capital. Revista Politécnica, São Paulo, n.10, p.181-196. jan. 1906.

MITROFF, Ian.

Norms and counter-norms in a selected group of the Apollo moon scientists: a case study of the ambivalence of scientists. American Sociological Review, Nashville, v.39, n.x, p.579-595. 1974.

MOTOYAMA, Shozo; NAGAMINI, Marilda. Escola Politécnica: 110 anos construindo o futuro. São Paulo: Epusp. 2004.
MULKAY, Michael.

Sociology of science: a sociological pilgrimage. Philadelphia: Open University Press. 1976

NADAI, Elza.

Ideologia do progresso e ensino superior (São Paulo, 1891-1934). São Paulo: Loyola. 1987.

NAGAMINI, Marilda.

1889-1930: ciência e tecnologia nos processos de urbanização e industrialização. In: Motoyama, Shozo. Prelúdio para uma história: ciência e tecnologia no Brasil. São Paulo: Edusp; Fapesp. p.185-232. 2004.

PUJOL JR., Gustavo Hipólito.

Uma estação modelo: Estação Mayrink, na E. de F. Sorocabana, projetada e executada pelo arquiteto V. Dubugras. Revista Politécnica, São Paulo, n.13, p.187-192. jun.-ago. 1908.

PUJOL JR., Gustavo Hipólito.

Dissertação. Revista Politécnica, São Paulo, n.4, p.148-167. abr. 1905.

RAMOS, Francisco Ferreira.

A eletricidade e a hulha branca em S. Paulo. Revista Politécnica, São Paulo, n.9, p.107-111. dez. 1905.

REVISTA...

Revista Politécnica, São Paulo, edição especial. fev. 1905.

RODRIGUES, Fonseca.

A ponte do aterrado do gasômetro. Revista Politécnica, São Paulo, n.4, p.193-201. abr. 1905.

SÁVIO, Marco A. C.

A cidade e as máquinas: bondes e automóveis nos primórdios da metrópole paulista, 1900-1930. São Paulo: Annablume; Fapemig. 2010.

SCHAFFER, Simon; SHAPIN, Steven.

Leviathan and the air pump: Hobbes, Boyle, and the experimental life. Princeton: Princeton University Press. 1985.

SCHWARTZMAN, Simon.

Um espaço para a ciência: formação da comunidade científica no Brasil. Brasília: Ministério da Ciência e da Tecnologia. 2001.

SHAPIN, Steven.

Pump and circumstance: Robert Boyle's literary technology. Social Studies of Science, London, v.14, n.4, p.481-520. 1984.

SOUZA, Antônio Francisco de Paula. Colação de grau aos engenheiros de 1904-1905. Revista Politécnica, São Paulo, n.6, p.360-376. jun.-jul. 1905. 
TIMOSHENKO, Stephen. P.; YOUNG Donavan. H. Theory of structures. New York: Mc-Graw-Hill. 1965.

VARGAS, Milton (Coord.).

Contribuições para a história da engenharia no Brasil. São Paulo: Epusp. 1994a.
VARGAS, Milton (Org.).

História da técnica e da tecnologia no Brasil. São Paulo: Unesp; Ceeteps. 1994b. 